\title{
NOTES ON THE INSCRIPTION ON A CARVED BONE FROM YUCATAN *
}

\author{
By Thomas S. BARTHEL \\ Universität Tübingen
}

The carved deer bone illustrated in Fig. 1 was reportedly found on the Island of Jaina, in the part of the Yucatan Peninsula and is now in a private collection in Los Angeles, California. ${ }^{1}$ So far unpublished, this piece is exceptional because of its engraved iconographical and epigraphical details. The following analysis is based on a drawing in the scale of 2:1 made by Hasso von Winning.

The relief decoration is composed of two parts. The upper part shows a human figure accompanied by glyphs; the lower but longer part consists of the twenty day signs of the Maya calendar. We shall first deal with the upper part. Identification of its accompanying glyphs presents difficulties particularly because the details in the center of the first and second glyphs are poorly preserved. The suffix of Glyph 1 might suggest a verbal expression; in other words a "thematic glyph" as is to be expected at the beginning of a text. The superfix of Glyph 2 appears to be reversed; similar glyphs (e. g. Glyphs 78, 84\$7, 228-229, 339 and 359 according to Thompson's Catalogue) always display the smaller element in the upper left. In the suffix one might recognize a variant of Glyph 142. If this is

* Translated from the German by Hasso von Winning.

1 Dr. Seth B. Benson of the Museum of Vertebrate Zoology, University of California, Berkeley, graciously attempeted to identify the bone specimen from a set of photographs submitted by Hasso von Winning. Dr. Benson wrote:

"It is difficulted to use the photographs since they do not show how much of the bone is actually missing. However, using shape as a criterion it seems certain that the bone resembles those of the deer specimens I used, more than it does those of mountain lion. In fact, there is so much similarity with deer that I think it unlikely that it was anything else we can be sure that your locality [Yucatan Peninsula] and dating [second half of the first millennium A.D.] are correct. But this is as far as I can go on the basis of the photographs." (Letter March 10, 1964). (IHvW) 
the case, our Glyph 2 would have a nominal function in accordance with the schematic structure of hieroglyphic clauses. In our Glyph 3 the main sign can be clearly discerned, although the contours are aberrant. It shows Glyph 508, a rare geometric rendering of chicchan. While the prefix remains dubious, the suffix may be related to Glyph 74 . A partial similarity with Glyph 74:508:74 on Stela 8 (south) at Naranjo is obvious (Maler, 1908, pl. 23). It is noteworthy that in both cases the respective texts end. All these observations, however, do not bring us closer to an understanding of the meaning of the three accompanying glyphs. Therefore we must attack the problem from another angle.

The seated figure, which is characterized by grooves around the toothless mouth as an aged male, wears elaborate ornaments on its head and back. Notemorthy is the breastplaque, suspended from a long necklace, which depicts an incised symbol that is related to similar forms in hieroglyphic inscriptions. Before attempting to analyze it we call attention to the pedestal on which the human figure rests. It is a throne covered by a mat. " "Mat" and "throne" obviously convey the well-known Maya-Yucatec concepts pop, $t z$ 'am meaning "reign", as is indicated in the books of Chilam Balam (e. g. Roys 1949:170 "...he takes over his government. He is declared, he is set up direct, he is established firmly in his command, at his cup, on his throne (tu tz'aam), on his mat (tu pop), on his seat", and also "...the time of the change of the mat, the change of the throne ( $u$ hel pop, $u$ hel $\left.t z^{\prime} a a m\right)$ ". A person privileged to sit on a mat spread over a throne, as shown in Fig. 1 , is undoubtedly a ruler. Whether he is a secular or divine ruler, a "king" or a god remains to be determined. It is sufficient for the present to keep in mind that the bearer of this specific breast plaque is an aged man seated on a throne.

This theme, expressed pictorially on the Yucatan bone carving has its epigraphic parallel in two Early Classic inscriptions

2 On both sides of the throne are two grotesque heads facing left. Between the quadrangular throne supports is a leg whosc zigzag lines undoubtedly in. dicate fur. Another furry leg is beneath the left head and oblong elements on the right probably are also legs.

Although the two animal heads cannot be identified with certainty as jaguars, it is apparent that they symbolize the throne as a two-headed jaguar seat. A similar device is-know from a Late Classic stone bas-relief at Palenque (Proskouriakoff, 1950, fig. 54, b). A second image of double-headed bench at Palengue is no longer in existence. (HvW) 
at Yaxchilan. Lintels 22 (B3) and 47 (G1) show Glyph 125.617:142v:139 (cf. also Morley 1938, p. 375, fig. 58, b).

The Main Sign with the first suffix can be considered a counterpart to the design on the pectoral; Lintel 47 clearly shows the slightly curved parallel lines; Lintel 22 seems to show the elements of the ladder design. Prefix 125, which we deciphered as ah indicates that the pectoral has a (male) "possessor". The rendering "The one with the (specific) pectoral", which presumably indicates a rank or function, is supplemented by the terminal suffix 139. It is not difficult to recognize in the T-shaped elements of Suffix 139 the stylized supports of the throne. We therefore understand the hieroglyphic examples from Yaxchilan to convey the phrase "The one with the (specific) pectoral on the throne". ${ }^{8}$

However, the inscription on Lintel 22 at Yaxchilan offers further insight. In A4 appears the Glyph 125.32.544:670:254. Prefix and Suffix are rendered similarly as in the preceding glyph, and are meant to express "The one... on the throne". Close observation of Maler's illustration reveals that the "throne suffix" contains fine hatching, probably indicating that the throne is covered by a mat. It should be noted that hieroglyphic Maya texts have a stylistic pecularity in the principle of "circumscribing repetition", that is, a method of enumerating names or titles, all of which refer to the same ruler or deity but express distinct functions or aspects. In reference to our Yaxchilan text, this means that Glyph B3 and A4 express only two aspects of the same individual: in each case it is "The one... on the throne" (there is a stylistic elegance in the partial sound equivalence $A h(X)$ tz'am / ah (Y) tz'am!) while the difference in the central elements obviously points out varying attributes or actions.

The still undetermined central element 32. 544:670 contains the word kin. The hand in Glyph 670 certainly expresses an action. In an earlier paper (Barthel 1963:172) we applied the reading $t z$ ' $a$ ("to give"), suggested by Knorosow (1955:66) . Proceding with due caution, we shall for the present assume

3 This interpretation opens further promising avenues of investigation for the decipherment of Affixes. Next to the occurrence of Glyph 139 the variant, Glyph 360, used only on the Early Classic Stela 31 at Tikal (cf. Barthel 1963) should be noted, as well as several occurrences of Glyph 254, unless they are not mere substitutions for Clyph 178, as can be observed in certain Yucatec inscriptions. 
that the combination $32.544: 670$ is to be understood as "an action referring to kin".

With this information in mind, let us return to the inscription on the carved bone, where we immediately encounter kin composed of twenty day signs which are arranged in two columns beneath the throne. The hand with extended thumb in Glyph 670 occurs also in the portrait of the Old Man on the Throne who holds out his left arm. His hand "scatters" something. We suspect in this gesture an equivalent to Affix 32 . Summarizing, we can say "The one... on the throne" is engaged in "scattering (something)", an action somehow related to the day signs. Thus, the Yucatec bone carving expresses in pictorial detail what is conveyed in condensed hieroglyphic form in the Yaxchilan clause 125.32.544:670:254. We propose that the action shown should be understood in the sense of prognostication of the days (Tagedeuterei) .

Actually two concepts are involved, the scattering of small curved objects and the calendrical interpretation of the written day signs. In Yucatec Maya Kintah, or kinyah, means "augurar, sacar agïieros de cosas naturales; apostar, echar suertes; adivinar por hechiceros" (Perez Dictionary, p. 177). In Kekchi k'ehic, k'ehibc or k'ehinc stand for "adivinar" (Sedat 1955:93); in Cakchiquel k'ijij, k'ijin, k'ijiniq has the meaning of "adivinar lo futuro, predecir, adivinar, el adivinar, el predecir" (Sáenz, 1940:211). Correspondingly the title of the priest versed in calendrics and the diviner is ah kin (Yucatec Maya), aj'k'e (Kekchi), aj k'ij (Cakchiquel), ah quih (Pokoman), etc. Interesting is the Cakchiquel cholol $k^{\prime} i j$ for "el que determina si el día es bueno o malo para alguna celebridad" (Sáenz 1940:210); "adivino, el que determina qué día será apto para alguna ceremonia (op. cit. p. 99). The Cakchiquel cholk'ij corresponds to the Yucatec tzolkin (cf. Thompson's doubts, 1950:97) .

The orderly columnar arrangement of the days on the carved bone could very well signify tzol-kin (cf. Motul, p. 264: $t z o o l=$ cuienta de carreras, hileras, hileras de gente; tzolcinah $=$ ordenar, poner en orden o rengleras; also Perez, p. 367 with numerous examples indicating that $t z o l$ signifies a sequential ordering. Furthermore, $t z o l$ (Kekchi) = linea, fila; tzolobanc $=$ alinear, poner cosas en fila o en orden; cholajir (Cakchiquel) $=$ poner en filas, ordenar; chol (Quinché) = "in eine Reihe 


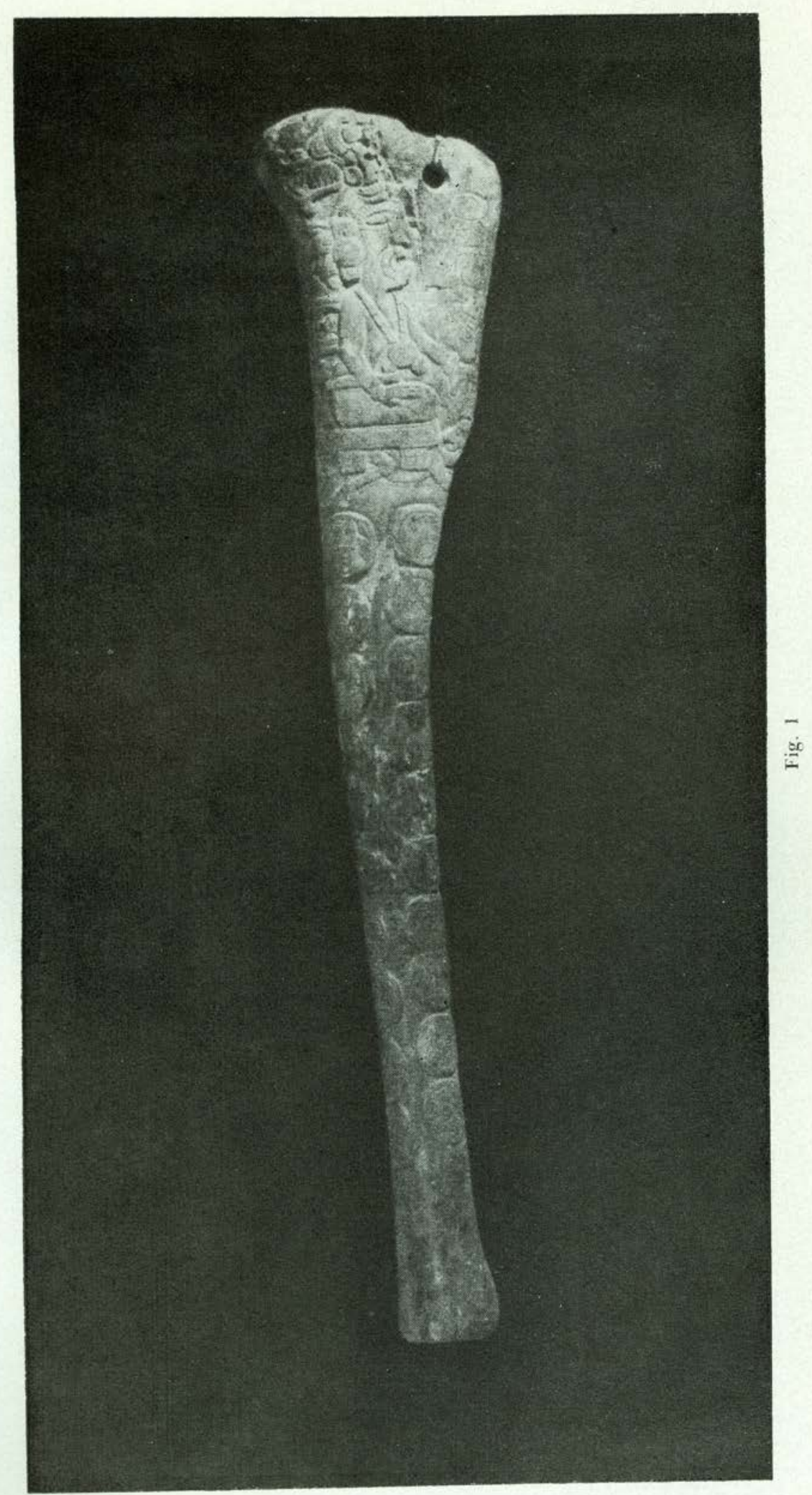



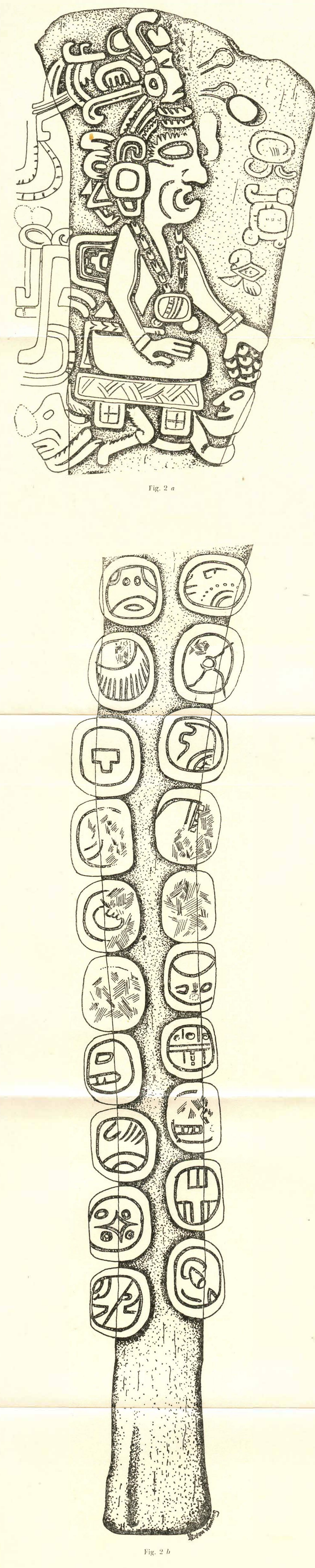
stellen, orden, aufzählen [to put in a row, ordering, enumerating] (Schultze-Jena, 1944:245). At any rate all twenty day signs of the Uinal are represented in proper sequence.

If our interpretation is correct the ritualistic examination of these day signs in the sacred calendar proceeds with the scattering of small objects from the hand of the Old Man on the Throne. Ethnographic investigations indicate that the modern Yucatec Maya of the Valladolid region use maize kernels when casting lots for divinatory purposes (Tozzer 1907:163-164), where as the Quiché use beans (Schultze- Jena 1933:42ff), The Quiché practice is particularly revelant, since the counting of the beans, wich are arranged in groups, leads to a specific day in the ritual calendar. Schultze-Jena comments (translated from the German original, 1944:43) "the name of the divinatory paraphernalia is derived from this procedure: is $\mathrm{imbal}$ kix from išim, maize kernel, corn, grain, granular substance etc., meaning here the bean, from the instrumental substantive ending lal combined with the abbreviated prefixed article ri, thus, "the kernel (susbstance) of the days" that is, the beans for determining the days. The manipulation of laying out the oracle is called $u$ kixbal, meaning "the thing, the means, to find the day..."

The custom of casting lots for purposes of divination has dicep roots in ancient Mesoamerica. We refer to a passage in the Popol Vuh, cited by Schultze-Jena (1944:13) and dealing with the mythological pair Xpiyacoc and Xmucane: "Alsabld fielen die Lose und fand die Anrufung statt, indem sie mit Maiskörnern und mit Tzitébohnen das Schicksal befragten" ["soon the lots fell and the oracle was called upon by interrogating the maize kernels and the tzite beans to determine the destiny']: cate puch $v$ cahic, $v$ quihiloxic ri xmalic chi ixim, chi tzite. The Old Man is the lord of the tzité bean (are ri mama are ahtzite), the Old Woman rules over the calendar days and birth-bound fate (are curi atit ahquih). Their counterparts in the Nahua sources are Oxomoco and Cipactonal (Sahagun, Florentine Codex; Codex Borbonicus 22; Seler 1904: 78-83, figs. 1-3) . Considering the curved shape of the objects used for lot casting, it would seem that beans rather than maize kernels are being scattered by the Old Man on the Throne. ${ }^{4}$

\footnotetext{
4 Earlier in the Popol Vuh the sex attribution of $X$ piyacoc and Ximucane is reversed: we equate there: "the vencrable one" (mamon) $=$ "our grand-
} 
Let us follow once more the corresponding hieroglyphic version at Yaxchilan. Preceding the title "The One with the (specific) pectoral seated on the throne" is a glyph which Thompson catalogued under $17 \mathrm{v}: 258: 528.528$ and which occurs exclusively on Lintels 22 and 47. Possibly this singular construction has to do with an individual name. Noteworthy also are the two glyphs which precede in each case:

Lintel 22

\section{A2 237. shaggy head:59 \\ B2 $74 \mathrm{lc}: 59$}

Lintel 47

B7 679:59?

A8 $741 \mathrm{lc}$ : 59

The suffix should be read all cases as $t i$ which, among other meanings, can be translated as "mouth" (Yaxchilan is situated in the Chol region). The Main Signs would indicate in each instance whose "mouth" it is, or what happens with it. Thompson (1962:62) sees in Glyph 237 ("shaggy head") a dog whose eye is being pecked out by a vulture (?), and refers to the expression col ich in the Yucatec sources. (Pio Perez, p. 55, explains the phrase as "castigo antiguo entre los indios para los amancebados"). For our purpose it is interesting that positional correspondence 679:59 can be translated with ch'eenti "silent mouth", among others.

The second glyph in each glyph pair refers to the "mouth" of a certain animal. Should this indicate certain significant animal sounds, perhaps in the sense of premonitory signs? However that may be it should be noted that the texts in the lintels deal with the motif "mouth", whereas the Old Man on the Throne is represented with his mouth open, as if he were speaking.

In the same context Lintel $22 \mathrm{Bl}$ shows another interesting glyph: Main Signs 535 and Suffix 23 which, taken together, we read as munal (Barthel 1963:198, note 143), whereas

father" (ca mam) $=$ Xmucane. If this attribution is correct-and it is in contextual agreement as well as with Schultze-Jena's commentary (1944:188-189), it could serve as a possible clue for interpretation of Glyph 617, which characterizes the Old Man on the Throne. We also suggest the possibility that Glyph 617 might be a phonetic intimation for the name Xmucane, and that is should be read as "muq ("enterrar, esconder" Kaufmann: 1963:120) a common root of Maya languages. In fact, other compounds of Glyph 617 tend to indicate that this symbol is associated thematically with the underworld, for reasons which cannot be given here. 
Thompson's Prefix 117 represents undoubtedly a jawless dragon head. This affix strongly suggests the mythical earth crocodile of the cipactli type. Could it be a coincidence that the ornament carved on the back of the Old Man on the Throne contains a central element that conspicuously resembles certain variants of Glyph 535? Likewise, it would seem that the contours of the back ornament (which appear on the curved left edge of the bone) portray a stylized dragon head or serpent head whose lower jaw is missing.

The Yaxchilan lintels contain numerous additional portraits of deities which, with better knowledge of Classic Maya religion should give insight into the characteristics of mythological beings. There is a strong probability that somehow they are to be considered patrons of the ritual calendar. We shall rcfer only to the head which in each case occurs in association with the "glyph for casting lots and choosing of days" the Glyph 1030 k (Lintel 22, B4 and Lintel 47, D4). This being apparently belongs to the multifarious group of the rain gods with their characteristic attributes, such as "torch, hatchet" etc. Keeping in mind the "rain" motif, we return once again to the representation on the carved bone.

Following our postulation that the relationship between the portrait of the Old Man on the Throne and the day signs below depends on the casting of lots for the purpose of prognostication of the ritual calendar, the problem arises whether there is anything in these signs that could reveal the result of the augural inquiry.

From a stylistic point of view it would seem that the rendering of the day signs is Early Classic, since various details are comparable to designs on the well-known fresco of Uaxactun (Structure B-XIII) . Such similarities would further justify the comparisons made earlier between the carved bone and the two Early Classic lintels of Yaxchilan. Although all twenty day signs are represented (several signs in the center part are not preserved because the bone had been broken and was recently repaired) the arrangement differs from the sequence costumarily expected. Neither does the enumeration begin (in the upper left) with imix, the first day in the ritual calendar, nor does the arrangement follow the usual pattern of hieroglyphic inscriptions which are read in pairs of glyphs from left to right and from top to bottom. Instead the following order appears: 


$\begin{array}{ll}\text { ahau } & \text { cauac } \\ \text { imix } & \text { etz'nab } \\ \text { ik } & \text { caban } \\ \text { (akbal) } & \text { (cib) } \\ \text { (kan) } & \text { (men) } \\ \text { (chicchan) } & \text { ix } \\ \text { cimi } & \text { ben } \\ \text { manik } & \text { eb } \\ \text { lamat } & \text { chuen } \\ \text { muluc } & \text { oc }\end{array}$

The order is reversed counter clockwise. The starting point would normally be the second sign in the first column: imix, descending to muluc and continuing in the second column from bottom to top, that is from oc to cauac. The final day ahau is then reached in a place where one normally should expect the beginning day imix.

The order of the day signs form a round; one might say the dog bites his own tail. A similar method of reading consecutive day signs in reversed order occurs in Codex Madrid 75-76, although comprising the entire ritual calendar in its division into four quarters.

Costumarily the sign in the upper left, in this case ahau, marks the beginning of a text. In calendrics, the ahau days serve to identify and conclude periods of time, such as tun, katun, etc. However, since no numerals occur in this inscription, we have no indication to imply a probable chronological position.

Let us therefore undertake a different approach, disregarding the purely calendric connotation of the day signs and considering them simply as normal, meaningful hieroglyphs of the Maya system of writing. In other words, could the Maya scribe have arranged these twenty day signs to express a strictly textual statement, perhaps even in the disguised form of an anagram, that might possibly contain the answer for the "choosing of days" obtained by the casting of lots?

If we set aside for a moment the problem of the reversed order of the calendar cycle and examine instead the pairs of day signs occurring in each horizontal line, we recognize a 
genuine hieroglyphic text. We shall therefore determine the primary significance of the calendar day, and occasionally investigate its alternative phonetic value. It is known that certain day signs are polyvalent. In the case of cauac this fact is gene-

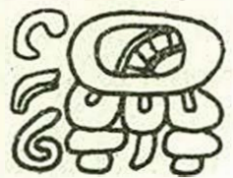

a

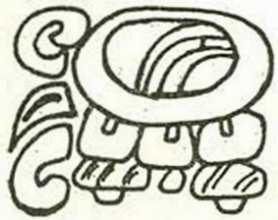

d

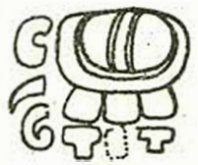

$b$

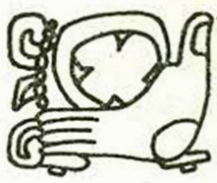

$c$

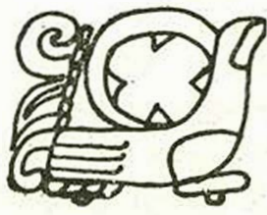

e

Fig. 3

rally accepted. In the case of imix however no general acceptance has as yet been attained, and in other signs (e.g. manik) polyvalence is still undetermined. Furthermore we will also consider more ancient, non-Yucatec names where needed.

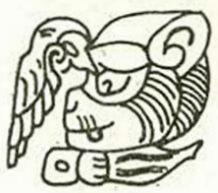

a

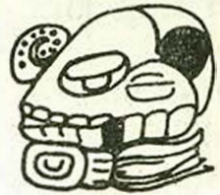

b

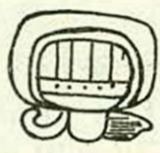

$c$

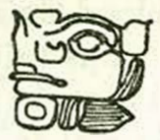

d

Fig. 4

The first hypothetical text pair is composed of the signs ahau and cauac. Assuming that ahau means primarily lord, ruler, king, the beginning of the text can at once be related to the pictorial representation above. The latter shows the mat and the throne ( $\left.p \circ p t z^{\prime} a m\right)$, precisely the insignia corres- 
ponding to a ruler. The lord (ahau) is apparently qualified by the following sign Glyph 528, whose non-calendric phonetic equivalent hab (haab, yab) is established. Combined, ahau hab can be translated as "lord of the rains" or "lord of the year".

The second pair of glyphs is composed of the day signs imix and $e t z^{\prime} n a b$. Following Thompson's hint (1950:73) other writers (Barthel 1954:10; Kelly 1962:25) have attempted to apply naab alternatively as a phonetic equivalent of imix.

Based on our yet unpublished investigations we find additional support to postulate that the polyvalence for imix is applicable in various hieroglyphic contexts and that nab, naab lend themselves to readings of homophones and homoiphones. Whether or not the Yucatec version of the second day sign as $e t z^{\prime} n a b$ is acceptable, there is no doubt that it stands for flint knife. We shall therefore consider the first glyph nab as a determinative for the following glyph "knife", in the sense of a play of words to signify "to besmear, to daub" (cf. Motul, p. 647 naabal $=$ untarse; nabaan $=$ cosa untada o ungida $o$ tiznada o ensangrentada; naabzah = untar o ungir, embarnizar, o tiznar; and in Perez, p. 231 among others nabal ti kik = ensangrentarse). The basic meaning of nab "to besmear oneself with", "to daub with" can be followed up in other Maya languages, e.g. Chol and Quiché. In Mesoamerican ceremonialism a "besmeared flint knife" can only mean a "blood-stained sacrificial knife". We therefore postulate that nab etz'nab (or nab tok or any other synonyms for a blood-stained flint knife) expressed in Maya hieroglyphs corresponds exactly to what the Mexican codices represent by a flint knife covered with red blood stains.

The third glyphic pair consists of the day signs $i k$ and caban. Taken at their face value "wind" (or "life") and "earth", we find that linguistically the combination ikcab is surprisingly a title of a priest (Pérez, p. 156, sacerdote). The function of this priest $i k c a b$ is not revealed in the documentary sources. On the basis of our glyph analysis a connection between the "blood-stained flint knife" and this priest would not be out of context. Consequently the second and third glyph pairs combined might perhaps read "blood-stained flint knife priest".

Of the following glyph pairs, which are partly damaged and can therefore be reconstructed only hypothetically, we shall only scrutinize the fourth pair. Akbal and cib can be understood as 
an ensemble probably correctly as a play of words akab ci "nocturnal intoxicating drink". Seler (1902: 490-491) had earlier pointed out a possible connection between the day sign cib and the beverage; cib could also be considered homonymic for the beginning of the verb cibezah (embriagar con vino; Pérez $\mathrm{p}$. 48). Ah ci is a drunkard; akab ci could correspondingly be interpreted directly as "one who drinks at nighttime". Thereby we apparently encounter a certain title from Early Classic Tikal, whose relationship with that of the High Priest of Sacrificial Rites in ancient Mexico was discussed recently (Barthel 1963: $168,170)$. Our interpretation is supported by the immediately preceding glyph pair which we translated as "bloodstained sacrificial knife priest". It was precisely "the one who drinks at nighttime" who carried out the function of a "priest with the blood-stained knife" when he gave the victim the last decisive blow.

Summarizing the interpretation of the text of the first eight glyphs in their peculiar order by applying their primary or secondary phonetic values, the following approximate reading can be given:

$\begin{array}{ll}\text { ahau haab } & \text { lord of the rains } \\ \text { nab etz'nab } & \text { stained knife } \\ \text { ikcab } & \text { priest } \\ \text { akab ci } & \text { the one who drinks at nighttimes }\end{array}$

The method of analysis which we have chosen is not as arbitrary as would seem at first glance. That the Maya used the day names as phonetic elements to devise plays of words is clearly demonstrated in the passage of the Chumayel dealing with the creation of the uinal (cf. Roys 1933: 116-119; Sodi Morales

\footnotetext{
6 The following observation refer to the remaining six glyph pairs which have not yet been analyzed, in order to point out possible ways for a later full interpretation.

Kan and men combined signify in a direct sense "corn master" or "corn maker", involving the ambiguity of the root kan for "precious", etc. We have already pointed out the probability that the Old Man carriers Glyph 535 on his back, the symbol of tender corn, and noted in the corresponding text on Lintel 22 at Yaxchilan the indication munal, which could be understood as a play of words for mun nal ("young maize plant" according to Koys 1933:115). At the most one might consider a phonetic approximation of kan and men, forming kamen, which means in Yucatec Maya "I received" or imperatively "receive". The attachment of the verbal suffix -en is also found in other text pairs.

Chicchan and ix apparently suggest a "sorcerer" who manipulated "serpents" in the sense of influencing the mythical rain serpents.
} 
1961: $211 \mathrm{ff})$. Although both the starting point and the theme vary, we gain insight into the kinds of associations between day signs and phonetically similar interpretations of an occurrence on a certain day that were typical Maya practice. Furthermore two statements from Chumavel are pertinent for the evaluation of our working hypothesis: After the creation if the uinal and of the world follows the phrase oxlahun tuc, uuc tuc, hun, upon which Roys justifiably commented: "The twenty daynames were combined with the numbers one to thirteen. When the numerical series of thirteen was completed, it began over again and was repeated for seven days more. Consequently we have 13 days +7 days $=1$ uinal" (Roys 1933: 118, note 3 ).

Thompson pointed out the sequential concordance between

Cimi and ben remind us of the play of words "death road" or, if based on the symbolism of the Mexican acall it could mean a "death-inflicting arrow". Taking the older form "cam which varies in the vowel sound, the reading camben suggests a possible play of words wiht Yucatec cambenil ("enseñanza y doctrina"). Such a notion of "teaching" or "learning" could have esoteric meaning relating to the deity proper or to his priest.

Little can be said about the pair manik and $e b$. Their symbolic value as day signs ("deer" for drought and the malinalli connotation of evanescence) would imply an unfavorable aspect. It would be necessary to investigate also the non-calendric phonetic comnation of Glyph 67l (chi) in its possible associations, as well as the meaning of $e b$ in the sense of "stairs" or "rows of teeth" etc.

Lamat and chuen also present considerable difficulties in interpretation. However, we can deduce the significance of lamat from a painted scene on a vase where it symbolizes, as pars pro toto, a rabbit; comparisons with Lowland Maya languages yield possibilities for a play of words with thuul. Besides, lamat can of course be related to the symbol of the Morning Star or to the Mexican equivalent tochtli (the rabbit in its association with the pulque deities). Chuen designates a craftsman and artisan. But we must point to a possible alternative: if the first svllable is taken for the Chol rendering chu (being equivalent with Yucatec $k u$ ), chu en could be translated as "good am I". In that case the preceding lamat sign would qualify the god either as god of the Morning Star or as pulque god or some other deity.

The last glyph pair is muluc and oc. $O c$ can be read according to its primary phonetic valuc, whereas muluc rather suggests a play of words with mul or muc. In the combination "to bury, cover, hide" (muc) plus "entering (down below) ", (oc) would imply the underworld or the region of the dead. It is also possible to gather "joint (mu!) entering (oc)" and consider the Aztec surname of the region of the dead in uilouinan, "where we all go" (Seler, 1923:20 after Sahagun). In the end we would have to disregard entirely the phonetic value of muluc and count upon its polyvalence. Ideographically this day sign represents "jade", a meaning which appeares to be better expressed by its highland equivalent toh (cf. among others toj, Kekchi "valor"; Cakchi. quel "pagar"). We emphasize the revelant substitution of precisely this day sign in Copan (cg. Thompson, 1950, fig. 8,8!). With Glyph 708 $=$ coh (cf. Xucatec coohil "preciosidad"; coohoch "cosa preciosa"). In this connection the reading "precious (things) enter (down below)" would remaindus of the "drops" which fall from above as rain or blood.

We believe that it is precisely the multiplicity of meanings in the readings which we have investigated that is instrumental in the disclosure of the secret contained in the glyph pairs on the carved bone. 
the patron gods of the numerals 1 to 13 and the patrons of the days caban to muluc (Thompson 1950: 88, 99, 131-136). We consider this equalization justified. An attempt to fit the series of the thirteen presiding gods to the day sign columns on the carved bone shows that the uinal would be covered in such a way that the left column (ahau to muluc = "4" to "13") plus the upper part of the right column (caban to cauac = "l" to " 3 ") compared with the remaining signs of the right column (oc to $c i b$ ) yield exactly a ratio of $13: 7$. Thus the left column terminates with the day whose patron is the one belonging to the highest numeral " 13 ". On the other hand, the right column begins at the bottom with a series of seven day signs without patrons. If the twenty day signs are listed in two columns forming a complete cycle, the only possible arrangement to obtain the disguised ratio of 13 to 7 is precisely the one outlined above.

Undoubtedly the calendar priest, familiar with the Series of Thirteen, was able to recognize at a glance in the bicolumnar arrangement " 10 plus 3 to 7". If, for instante, the cycle had been altered by one day so that the beginning in the upper left would be imix, the balance would have been disturbed because in the Series of Seven of the right column one element would have had to be placed in the left column. On the other hand, if caban had been in first place the Series of Seven would indeed have fitted in the right column, but the intended ratio of corresponding text pairs (i.e. the two horizontally adjoining day signs of all ten pairs) could not have been achieved. Only with ahau at the beginning is one able to obtain the 13:7 ratio of the uinal, as well as solve the anagram of this esoteric text!

The chapter in Chumayel concludes with the statement $u$ tzolan kin zanzamal licil $u$ xocol $u$ chun ti likine hebix tzolanile which Roys (1933: 119) translated: "Every day is set in order according to the count, beginning in the east, as it is arranged." Sodi (1961: 219) translated: "la lectura de la cuenta de los días, uno antes que el otro, empieza por el oriente, así como su relación".

Above, we attempted to establish a connection between the twenty day signs grouped in pairs and the tzol-kin; in fact, $u$ tzolan kin zanzamal expresses the very same thing. We suggest, however, the consideration of the possibility that Glyph 670 ("Hand with glyph in angle") as such signify tzol, being derived from the "action of measuring, ordering". 
The very peculiar arrangement of the twenty days composing a uinal into two columns (beginning with ahau in descending order, and ascending from $o c$ ) resembles a rectangle with two long and two narrow sides. Considering the persistent tendency in Maya mentality toward keeping all things in harmony with the world order, the question arises whether this rectangular arrangement could in some way be oriented with the cardinal points. ${ }^{6}$

In the only comparable parallelism illustrating a reversed cycle of day signs (Codex Madrid 75-76) the terminal (13) ahau is associated with the south beginning with (1) imix associated with the east. Also the Chumayel text mentions the east as the starting point. Applying these directional associations to the days shown on the carved bone the orientation would be as follows

$\begin{array}{ll}\text { left side } & =\text { east } \\ \text { right side } & =\text { west } \\ \text { upper (narrow) side } & =\text { south } \\ \text { lower (narrow) side } & =\text { north }\end{array}$

We believe that this assumption can be supported. The corner stones of this system are apparently ahau (starting point in the upper left of the first column) and $o c$ (starting point at the bottom of column 2). The patron of ahau is the sungod. $O c$ symbolizes the dog who descends into the underworld as the companion of the dead and of the dead sun respectively. If, therefore, we equate the abode of the sun with the south, it seems logical that the abode of the Dog of the Underworld should be related to the north.

In Codex Madrid 75-76 a nummy bundle (to be incinerated?) of the south is contrasted with a human sacrifice of the north. It is thus not difficult to recognize the accompanying deities of the northerly direction as the lords of the underworld.

Looking at the "magic rectangle" from the point of view of the symbolic connotation of its day signs, the following elernents can be substituted in the four corners:

\footnotetext{
6 The artist who carved inscription took care in scraping away the empty space between the ovals of the day signs, so that the latter appear raised about $1 \mathrm{~mm}$ above the background. In this way he succeeded in giving the text the appearance of a stone carved stela-like inscription. The details in the day sign oval are indicated by incised lines. (HvW)
} 


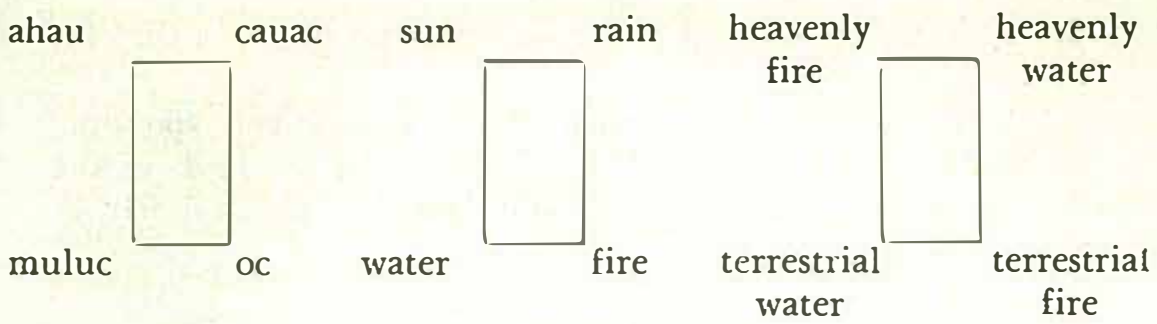

It is evident that similar elements occur in a diagonally opposed position. The elements which appear on the upper side of the "magic rectangle" actually pertain to the "upper region" (sun and rain clouds in the sky), whereas those at the bottom (on the opposite side of the rectangle) pertain to the

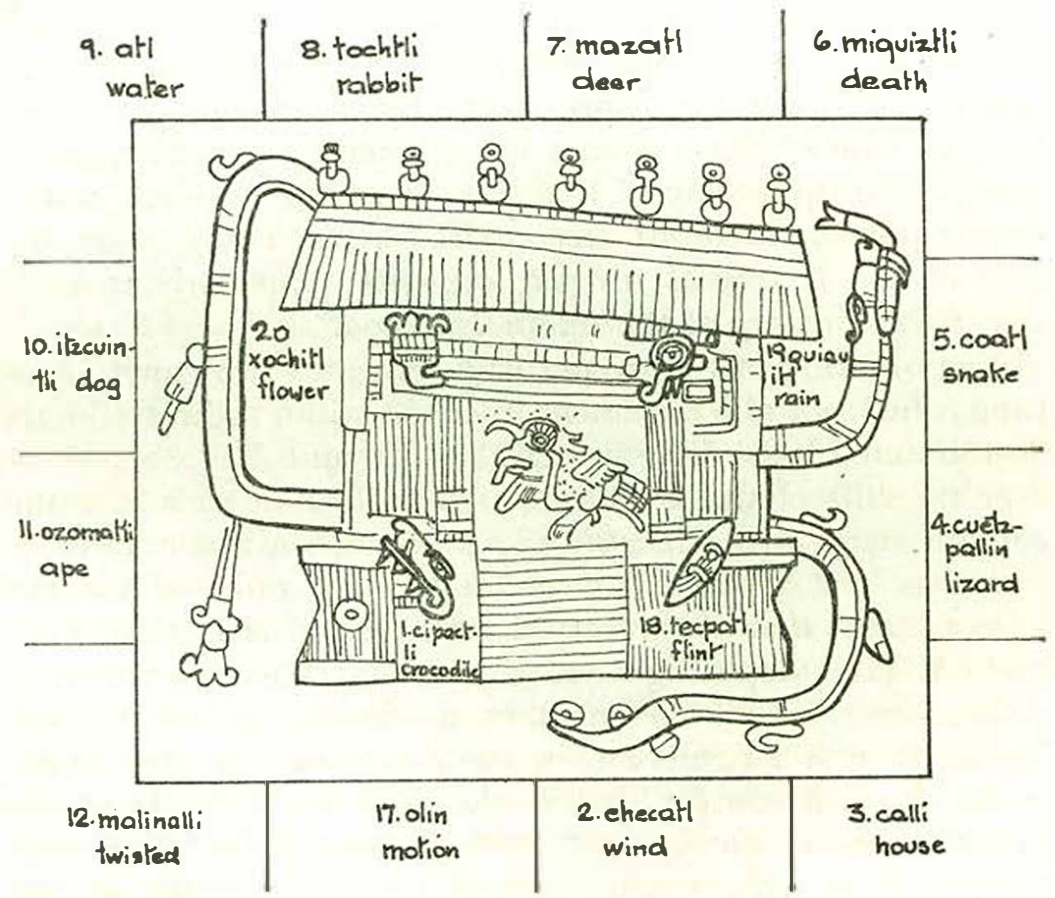

Fig. 5

"lower" region. The dichotomy of the elements fire and water, which had great importance in ancient Mesoamerican religious thought, is in this case schematically expressed, as it were, on two cosmic levels. Viewed in the regular order of the twenty 
day cycle the symbol for water in each case precedes that for fire.

If one attempted to devise a similar scheme corresponding to Nahua calendrics (based, for instance, on the lords of the days in the Borgia Group; cf. tabulation by Spranz, 1964: 4) the following arrangement would result:

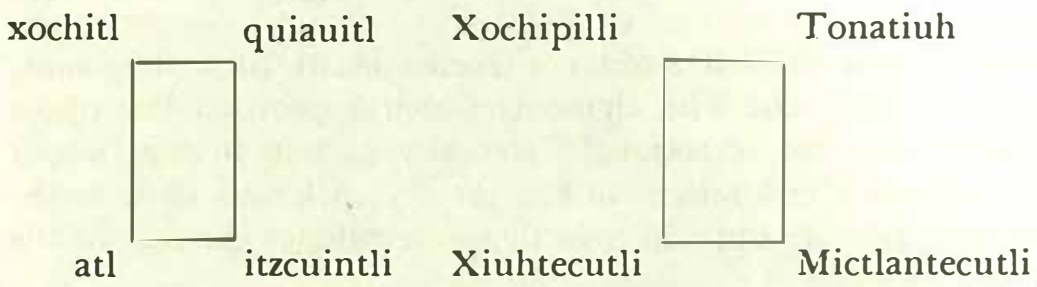

The deities at the top level (the young and the mature sungod) again characterize the "upper", the heavenly region, whereas the two "lover" level deities are associated with the underworld. The dichotomy of fire-water is at once evident at the corner points, where atl (terrestrial water) stands under the rule of the terrestrial firegod; quiauitl ("heavenly water") under the lordship of the celestial firegod.

The ordering of the twcnty day signs into two counterrunning columns is also document in the Mexican codices (Borgia 9b-13b and 13a-9a; Vaticanus B, 28a-32a and 32b-28b). However no shift of the beginning sign occurs; in each case the column starts with cipactli. We know of only one instance where at least a partial concordance of the order of the day signs matches that of the carved bone. It occurs in Cod. Vaticanus B (14), depicting a jade-decorated temple enshrining a turkey. Seler (in his Commentary, p. 75) interpreted it as the "house of rain", signifying, in the cosmic aspect, the "house of the clouds in the sky" and in the calendric sense "the rainy season". Furthermore, this "heavenly house of rain" is surrounded by a serpent. Only four day signs are shown in the central part: one pair flanks the entrance to the temple at the level of the lintel, another pair is seen by the stairs at the base. They appear in the following position:

$\begin{array}{ll}\text { xochitl } & \text { quiauitl } \\ \text { cipactli } & \text { tecpatl }\end{array}$


In other words, the Mexican rendering corresponds exactly to that of the four uppermost glyphs on the carved bone

$\begin{array}{ll}\text { ahau } & \text { cauac } \\ \text { imix } & \text { etzinab }\end{array}$

Twelve additional day signs frame the "house of rain" and should be read crosswise in conjunction with the central glyphs by the stairs. The starting point lies outside, at ollin. The reading continues inside with tecpatl, while the sequence from cipactli (inside) via ehecatl (outside) proceeds in usual order to malinalli, leaving a gap of four days (acatl to cozcaquauhtli). In its configuration the temple appears to be encircled by a loop composed of day signs. Unfortunately no parallels for this design occur in other codices which could help to clarify its significance.

Nevertheless, it should be stressed that the text pairs which we have interpreted as the Maya version of "Lord of the rains" and "blood-stained knife" match the Mexican symbolism "turkey" (the animal associated with Tlaloc; thus generally speaking the "Lord of the rains") and "serpent" (with the attributes knife-eye-bone dagger plus flower, thus "sacrificial blood"), or precisely those animals which illustrate the parallel in Codex Vaticanus B, 14.

We should also consider the possibility that the image of the Old Man on the Throne has double meaning, signifying not only the act of casting lots portrayed by the gesture of scattering but, in addition, the scattering of blood in the sense of ritual blood letting to insure the fertility of the earth.

Assuming the veracity of this second, somewhat disguised, aspect the meaning of the third glyph pair (ik and caban) would refer directly to "life (for those on) earth".

With our interpretations we do not believe to have lost our way in a maze of our own doing (although corrections and clarifications are to be expected). Yet, the double meaning strikes us as being deliberately conceived and as an accomplishment of utmost sophistication in rendering a text intended for the learned priest.

We have pursued two plausible lines of approach in our attempt to interpret the motifs on the carved bone: by point- 
ing out parallels in Early Classic Yaxchilan stone sculpture on the one hand, and in a Postclassic Nahua codex on the other. It does not necessarily follow that we are confronted with an alternative between the two. ${ }^{7}$

\section{BIBLIOGRAPHY}

BARTHEL, T. S. 1955. Versuch über die Inschriften von Chich'en Itzá Viejo. Baessler-Archiv N. F. vol. un: 5-33. Berlin.

_. 1963. Die Stele 31 von Tikal. Tribus No. 12:159-214. Stuttgart.

Kaufmann, T. 1964. Materiales lingüisticos para el estudio de las relaciones internas y externas de la familia de idiomas mayanos. Desarrollo Cultural de los Mayas 81-136. México.

Kelley, D. 1962. Fonetismo en la Escritura Maya. Estudios de cultura maya, vol. II: 277-318. México.

Knorozov, J. 1955. La Escritura de las Antiguos Mayas. Moscú.

Maler, T. 1903. Researches in the Central Portion of the Usumatsintla Valley. Peabody Museum, Harvard Univ., Memoirs, vol. IV No 2. Cambridge.

- - 1908. Explorations in the Department of Peten, Guatemala and adjacent region. Peabody Museum, Harvard Univ., Memoirs, vol. Iv, № 2. Cambridge.

Morley, S. G. 1938. The Inscriptions of Peten. Publications, Carnegie Institution of Washington, № 437.

Motul, Diccionario de (Maya-Español). 1929. Mérida.

Pérez, P. 1866-77. Diccionario de la Lengua Maya. Mérida.

Roys, R. 1933. The Book of Chilam Balam of Chumayel. Publica. tions, Carnegie Institution of Washington, No 438.

- 1949. The prophecies for the Maya tuns or years in the books of Chilam Balam of Tizimin and Mani. Publications, Carnegie Institution of Washington, № 585, Contrib. 51.

Sáenz de Santa María, C. 1940. Diccionario Cakchiquel-Español. Guatemala.

7 After completing this study a clay figurine from Jaina came to our attention which embodics a combination of symbols that could serve as tertium comparationis (Kimball 1960, pl. 44). This figurine portrays an old (bearded?) dignitary seated upon an outstretched jaguar inside a temple decorated with a Tlaloc mask. It cvidently represents a temple devoted to the raingod with his priestly functionary on a jaguar throne. The symbolism of the temple would seem to correspond to that of the "Temple of the 'Turkey" (i.e. the animal characteristically associated with Tlaloc) in Cod. Vaticanus B 14, as well as to the symbols of authority (Old Man on the Jaguar Throne) shown on the carved bone. 
Schultze-Jena, L. 1933. Indiana, vol. I: Die Quiché von Guatemala. Jena.

--. 1944. Popol Vuh. Das heilige Buch der Quiché-Indianer von Guatemala. Stuttgart-Berlin.

Sedat, G. 1955. Nuevo diccionario de las lenguas $K^{\prime} e k c h i$ y Española. Chamelco.

SEler, E. 1902-23. Gesammelte Abhandlungen zur Amerikanischen Sprach-und Alterthumskunde. 5 vols. Berlin.

—_. 1902. Codex Vaticanus Nr. 3773 (Codex Vaticanus B). Eine altmexikanische Bilderschrift der Vatikanischen Bibliothek. Berlin.

Sodi Morales, D. 1961. Cómo nació el Uinal. Estudios de cultura maya, vol. I: 211-230. México.

SPRANZ, B. 1964. Göttergestalten in den mexikanischen Bilderhandschriften der Codex-Borgia-Gruppe. Wiesbaden.

Thompson, J. E. S. 1950. Maya Hieroglyphic Writing. Publications, Carnegie Institution of Washington, Ne 589.

- 1962. A Catalog of Maya Hieroglyphs. Norman.

Tozzer, A. 1907. A Comparative Study of the Mayas and the Lacandones. New York. 